\title{
Stakeholder Understandings of Wildfire Mitigation: A Case of Shared and Contested Meanings
}

\author{
Joseph G. Champ · Jeffrey J. Brooks • \\ Daniel R. Williams
}

Received: 15 March 2010/Accepted: 22 June 2012/Published online: 11 August 2012

(C) Springer Science+Business Media, LLC 2012

\begin{abstract}
This article identifies and compares meanings of wildfire risk mitigation for stakeholders in the Front Range of Colorado, USA. We examine the case of a collaborative partnership sponsored by government agencies and directed to decrease hazardous fuels in interface areas. Data were collected by way of key informant interviews and focus groups. The analysis is guided by the Circuit of Culture model in communication research. We found both shared and differing meanings between members of this partnership (the "producers") and other stakeholders not formally in the partnership (the "consumers"). We conclude that those promoting the partnership's project to mitigate risk are primarily aligned with a discourse of scientific management. Stakeholders outside the partnership follow a discourse of community. We argue that failure to recognize and account for differences in the way risk mitigation is framed and related power dynamics could hamper the communicational efforts of the collaborative partnership and impact goals for fuels reduction. We recommend ways that both groups can capitalize on shared meanings and how agency managers and decision makers can build better working relationships with interface communities and other external stakeholders.
\end{abstract}

J. G. Champ ( $\varangle)$

Department of Journalism and Technical Communication, Colorado State University, Campus Delivery 1785 C-215 Clark Bldg, Fort Collins, CO 80523-1785, USA

e-mail: joseph.champ@ colostate.edu

\section{J. J. Brooks}

Division of Conservation Planning and Policy, United States Fish and Wildlife Service, Anchorage, AK 99507-5370, USA

D. R. Williams

Rocky Mountain Research Station, United States Department of Agriculture Forest Service, Fort Collins, CO 80526, USA
Keywords Circuit of Culture - Communication · Community - Frames of reference - Fuels reduction . Partnerships · Qualitative methods · Science · Wildfire . Wildland-urban interface

In some parts of the world, a number of factors have synergistically contributed to an increased risk of loss and damage from wildfires. Some of the factors include changing climatic conditions (McKenzie and others 2004; Westerling and others 2006); steadily increasing numbers of people living in interface areas, which are communities and other private lands located in or near fire-adapted forests and semiarid scrub (Davis 1990; Hammer and others 2007; Radeloff and others 2005; Shumway and Otterstrom 2001); and a century of aggressive wildfire suppression and exclusion policies, especially in western portions of the United States (Busenberg 2004; Cohen 2008; Dale 2006; Donovan and Brown 2007; Paveglio and others 2009). In western regions of North America and parts of Australia, for example, we are witnessing an increase in frequency of large destructive wildfires with catastrophic results for interface communities (e.g., Beringer 2000; Buxton and others 2011; Gorte 2008). Wildfires of this nature have killed people and domestic animals; disrupted watersheds; and destroyed public natural resources, private lands, homes, and communities. The National Academy of Public Administration (2004) reported that interface communities are evolving faster than they are creating defensible space and faster than their local governments' capacities to regulate fire-safe development. Wildfires are inevitable (Gorte 2008), and further losses and conflicts related to living in interface areas are likely to occur (Radeloff and others 2005). 
The setting for this study is in Colorado in the western United States. Foreshadowing the current situation in the United States, Cortner and Gale (1990) and Davis and Marker (1987) characterized wildfire in interface areas as one of the most contentious and elusive problems faced by government agencies responsible for wildland fire protection. Wildfires and uses of fire by managers in interface areas are not simple management problems, and there is no one correct or optimal solution. This is compared with a "tame problem," in which all stakeholders have a clear mission and one agreed-upon solution that can be achieved in a rationally engineered manner (Allen and Gould 1986; Brooks and Champ 2006; Rittel and Webber 1973; van Bueren and others 2003). Wildfire in interface areas and options for mitigating its risks present stakeholders with challenges and dilemmas that are shrouded in uncertainty and complexity (Carroll and others 2007; Gill and Stephens 2009). We define a stakeholder group as a collection of people sharing a common interest, activity, way of life (e.g., culture), or relationship to the outcome of an environmental-management decision (Findley and others 2001).

Brooks and others (2006a) argued that increased human settlement in fire-adapted areas is primarily a social dilemma: Whereas it is unanimously agreed that wildland fires can be physically dangerous for human life and property, people's understandings of the problem vary greatly, and perceptions of the risks are defined differently by land managers, policymakers, and interface community residents (Carroll and Daniels 2003; Slovic 1999). How the numerous and diverse stakeholders understand and define the issue of wildland fire and its risks largely determines how the problem will be addressed (Brenkert-Smith and others 2006; Cheng and Becker 2005). The wildland fire problem is socially complex because stakeholders often define and communicate the problem from differing vantage points or perspectives. These differing perspectives can be thought of as different frames of reference that people and groups use to make sense of information and assign value to that information for their daily lives (Weber and Word 2001). Wildfire-risk mitigation means different things to different people, and the various perspectives (i.e., frames of reference) for understanding it continue to evolve.

In response to the current wildland fire situation in the United States, agency land managers are working to strategically fulfill policy goals and directives to decrease the risk of wildfires to interface communities and protect landscape values (e.g., Forests and Rangelands 2011; Western Governors Association 2001). The primary objective is to make forests healthier or more like preEuropean settlement conditions, in which wildland fire was thought to be a rejuvenating aspect of these landscapes rather than a perennial threat. The management strategy is to restore fire-adapted ecosystems and resilient landscapes (Forests and Rangelands 2011; Healthy Forests Restoration Act of 2003; Western Governors Association 2001). The policy directives generally mandate a decrease in the amount of flammable organic matter on the land (i.e., fuel) by mechanically removing it, burning it under carefully controlled conditions, thinning by removing mature trees, or different combinations of treatments.

Researchers have found evidence that substantial support exists for prescribed burning and thinning among certain groups of citizens in the United States, but confidence in the management agency to successfully implement these treatments is low in some cases (e.g., Shindler and others 2009b). There are other challenges associated with options for treating fuels as a means to proactively mitigate wildfire risk. Different stakeholder groups have voiced ecological, social, and political concerns with treatment options (Carroll and others 2007); they vary in their acceptance of treatments (McCaffrey and others 2008); and they differ in their willingness to take action to decrease risks (Nelson and others 2004). Although communities in different geographical locations may value their forested landscapes for similar reasons (Nelson and others 2004), their concerns and opinions regarding treatment options can differ from place to place (Brunson and Shindler 2004; Shindler and others 2009a). Arvai and others (2006) found that people do not necessarily hold well-formed opinions about alternatives for wildfire-risk mitigation but instead construct their preferences in response to the cues they receive in how the issue is framed or presented to them.

Given these challenges, proactive management of wildland fire (including fuel-reduction strategies) requires much more trust (Lijeblad and others 2009; Winter and others 2004), collaborative learning (Daniels and Walker 1996; Schusler and others 2003), place-based planning (Cheng and Mattor 2010), and interactive communication and relationship building with the public (Paveglio and others 2009; Shindler and Toman 2003; Toman and others 2006) than fire exclusion and suppression, which are largely reactive and expert-driven. In the context of wildfirerisk mitigation, public land managers are being asked to play a much different role today than they did in the past (Shindler and others 2009b). Decreasing wildfire risk is a shared responsibility, and land managers seek matching cooperation and participation from municipalities and private landowners in fire-adapted areas where they may have limited or no management authority. Without this support, managers foresee that untreated private lands will leave pockets of unhealthy, highly flammable forest scattered throughout the landscape, which may threaten both public lands and nearby residential areas. To successfully meet 
policy directives to decrease the presence of fuels on public and private lands and create fire-adapted communities, land managers have been urged to organize, plan, and communicate in ways that will encourage broad support, engagement, and cooperation from the public (Dale 2006; Healthy Forests Initiative 2002; Shindler and others 2009a; United States Department of Agriculture [USDA] Forest Service 2003). Land-management agencies (and other institutions responsible for wildland fire and fuels management) have been encouraged to introduce improved processes to allow managers and the public to make better informed decisions about wildfire-risk mitigation (Arvai and others 2006).

\section{The Front Range Fuels Treatment Partnership}

The Front Range Fuels Treatment Partnership (the partnership) in Colorado, $\mathrm{USA}^{1}$ is one example of the growing call for improvement in agency efforts to address wildfirerisk mitigation through collaborative processes. The partnership was formed after the 2002 wildland fire season and the Hayman fire, which burned 136,000 acres and destroyed 600 structures in the mountains and hills west of Denver (Russell 2003; Shindler and others 2009a). This consortium of natural resource-management agencies is comprised of the Arapaho-Roosevelt National Forest, PikeSan Isabel National Forest, United States Forest Service Rocky Mountain Research Station, and Colorado State Forest Service.

The partnership's goal is to decrease wildland fire intensity by restoring fire to its more historic role in the landscape. Their plan for doing so includes facilitating communications, relationships, and collaboration among land managers and policymakers at the federal, state, and local levels, as well as private land and home owners and other stakeholders outside the partnership. These key players are to work together to identify strategies to mitigate wildfire risk by treating fuels on the land, such as burning away underbrush and small trees and shrubs in a controlled way or cutting and physically removing such material from the landscape. The partnership, aided by its public affairs officers, creates effective outreach messages about how to decrease the threat of wildfire and transfer those messages to local governmental institutions and large and small private landowners to educate and encourage support for decreasing fuels and related management actions (Brooks and others 2005; Shindler and others 2009a; USDA Forest Service 2003).

\footnotetext{
${ }^{1}$ Colorado's 'Front Range' is a subalpine zone bordered by the Great Plains to the east and the Rocky Mountains to the west that stretches from the Wyoming border south to Pueblo. The state's largest cities lie in this region as well as $85 \%$ of its population.
}

\section{Study Purpose}

Our case study focuses on the communications work of the partnership. Our research purpose is to compare formal members of the partnership, such as expert managers and policymakers (i.e., a group we labeled "producers") with stakeholders outside the partnership, such as private landowners and other members of interface communities (i.e., a group we labeled "consumers") in the context of how they understand and frame wildfire-risk mitigation. The ways in which the producers and consumers understand this issue result from shared (or different) "mental models" or social "constructions of the world around them" (Paveglio and others 2009, p. 78; see Zaksek and Arvai 2004 for a cognitive approach to mental models in risk communication). We assumed that these socially constructed understandings (or meanings) of wildfire-risk mitigation are created and negotiated by way of communication, exist in language and discourse, and change according to time and place (Paveglio and others 2009). We examined how meanings of wildfire-risk mitigation were shared between the producers and consumers and how meanings differed to learn how socially constructed meanings are negotiated in this case of stakeholder collaboration.

Two primary questions guided our effort to compare how producers and consumers construct and communicate meanings:

1. How are these meanings being shared or not? In other words, in what ways did meanings surrounding wildland fire issues in the Front Range of Colorado, USA, overlap for these groups, or not, and why?

2. How might we use this knowledge to account for the negotiation of meaning related to the partnership's endeavor? For instance, if there are differences between producers and consumers, how are these differences being used in the construction of meaning? In other words, how might one meaning (or sets of meanings) be competitively established and prioritized over others at the loss of those who might construct alternative meanings or those who define the issue differently than the partnership?

\section{The Circuit of Culture}

To this purpose, we applied a theoretical model of human relations and communication known as the Circuit of Culture (Acosta-Alzuru 2003; Benwell 2003, 2005; Burgess 1990; Champ 2008; Champ and Brooks 2010; Curtin and Gaither 2005, 2006, 2007; Dean and Jones 2003; Levine 2001; Norton 1996; Soar 2000; Squire 1993, 1994a, b; Taylor and others 2002; Terry 2005; Wilcox 2003). 
Scholars of cultural studies argue that researching socially constructed meanings (and making statements about those meanings in the context of environmental communication) is only appropriate after one has accounted for important elements of human relations and culture. Ultimately, researchers who apply the Circuit of Culture model are interested in what Hall (1997, p. 6) called the "effects and consequences" of certain structural arrangements of cultures and societies. This model, Hall wrote, seeks to examine how a given arrangement, such as the partnership, "connects with power," regulates behavior, constructs identities, and defines how "things are represented, thought about, practiced, and studied." Based on this model, we assume that human relations occur not in a static environment but in a broad process that evolves with time.

\section{Cultural Processes}

The Circuit of Culture is theorized and applied in terms of five interrelated "cultural processes" (du Gay and others 1997, p. 3): production, consumption, identity, representation, and regulation (Fig. 1).

\section{Production}

"Production" (du Gay 1997) represents the creation of many forms of goods, services, and experiences. It is crucial to consider the way institutional constraints (e.g., federal policies) limit or at least control the way these goods, services, and experiences are produced (i.e., attempts to encode particular meanings; see Curtin and Gaither 2005, p. 100). We view the partnership's efforts to create and disseminate a particular message of wildland fire management and fuels reduction to be a process of cultural production.

\section{Consumption}

"Consumption" (Mackay 1997) is the act of decoding (Hall 1980) these goods, services, and experiences

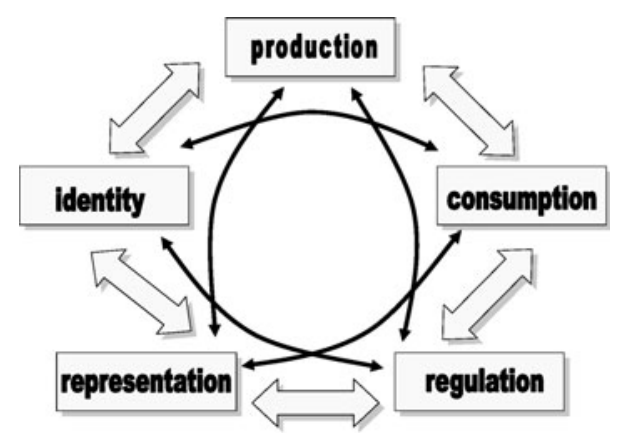

Fig. 1 Circuit of Culture (du Gay and others 1997) produced by the culture. Decoding is the process in which we "appropriate and make sense of various cultural forms in our routines in everyday settings" (Mackay 1997, p. 1).

\section{Identity}

"Identity" or "identities" (see Woodward 1997) are "types" (du Gay and others 1997, p. 15) or "social profiles" that groups and individuals use to assign meaning to people, places, things, or events (Champ and Brooks 2010). The frequency and complexity with which humans share stories of identity are one of the characteristics that make us unique in the animal kingdom.

\section{Representation}

These stories are told within the process of representation (Hall 1997). "Representation" "stands for the way language... can play a fundamental role in meaningful experience. Languages establish and essentially hold meanings in place by defining how things and concepts are different or similar to other things and concepts" (Champ and Brooks 2010, p. 574). Language is a process that influences meaning, and the language and symbols used to produce messages for public consumption matter a great deal. It is easy to think of representation in terms of real texts that people can experience, such as agency reports, news releases, brochures, and Web sites disseminated to public audiences.

\section{Regulation}

"Regulation" is the final process in the Circuit of Culture model and includes formal governmental policy as well as informal, on-the-ground social norms and other types of social- or self-regulation (Champ and Brooks 2010; Thompson 1997). We did not specifically focus on regulatory processes related to the partnership's work on wildfire risk mitigation in this study.

\section{A Theory of Meaning}

Researchers who examine human relations and communication using the Circuit of Culture model argue that meaning is dependent on the way these five processes interrelate. These interrelationships may seem static, even permanent, or they might seem quite fluid and subject to change depending on conditions from one time or place to the next. The connection or overlap among and between the processes is called "articulation" (Curtin and Gaither 2005, 2006, 2007; du Gay and others 1997; Hall 1994, 1996, 1997; Taylor and others 2002). The arrows in Fig. 1 
capture this sense of overlap among and between the five processes (du Gay and others 1997). The meanings that individuals and groups create, hold, and attribute regarding environmental problems are related to the nature of the articulations or overlap among and between the processes in this model. In other words, meaning is understood in the way that people find these five cultural processes to interact in their daily experiences as observers of and participants in a culture and its social arrangements, such as collaborative resource planning and management (e.g., the partnership).

We assume that the producers hold particular meanings and understandings of wildfire risk mitigation that they intend to transmit to consumers in the form of media (e.g., Web sites and brochures) and face-to-face communications (e.g., public meetings, education sessions, and one-on-one interactions). The producers assume that their understandings of the problem will be interpreted as is (retaining original meaning) by consumers when they read or experience these media and interpersonal communications. Consumers also create representations on their own during interpersonal interactions (e.g., community meetings) and increasingly in the form of online communications (e.g., social media, blogs, and emails). The partnership produces various messages in its work, but the meaning of these messages is not ultimately defined at the moment of production. Although meaning is a process that is often substantially influenced by the act of production, meaning continues into the moment of consumption as consumers interpret messages from their position and on their own terms (Hall 1980).

\section{Methodology}

We focused on the experiences of two groups of people involved in the work of the partnership. Specifically, we described and compared meanings for producers and consumers. We examined the overlap (i.e., shared meanings) and the lack thereof (i.e., differing or contested meanings) between the cultural processes of production and consumption in the partnership's effort to communicate about wildfire-risk mitigation. In this case, the producers are land managers and policymakers, and the consumers are members of the general public and private landowners. We used interviews and focus group discussions to represent meanings for the producer and consumer groups. As described later in the text, discussions were further captured by video and audio recordings and ultimately, transcripts, which provided the data for our analysis.

Our methodological approach was guided by a research paradigm known as "productive" (Patterson and Williams 2002) or "philosophical" (Freeman 2006) hermeneutics.
These investigators describe the interview/focus group setting as the active coconstruction of meaning and understanding among participants and researchers. According to this approach, people use dialog to construct the meanings that make up their realities, and these realities are best thought of as emergent narratives (rather than predictive outcomes resulting from pre-existing social, psychological, or environmental variables). Unlike the inductive orientation of Glaser and Strauss's Grounded Theory approach (1967), productive hermeneutics holds that the researcher undertakes his or her study with preconceived theories about how the social world works (Patterson and Williams 2002, p. 23). In our case, we assumed that an investigation of the communication efforts of the partnership would show shared and contested meanings of wildfire-risk mitigation and perhaps relations of power and authority between those working inside and outside the partnership.

We interviewed a sample of producers and consumers who could openly discuss the partnership's goals, objectives, and strategies (Holtzhausen 2000). We chose focus groups and qualitative interviews because of their flexibility, potential for active dialog, and ability to both construct and capture meanings (Greenbaum 2000; Lindlof and Taylor 2002; Mishler 1986a, b; Paveglio and others 2009). All interviews were jointly conducted by two of the investigators. We used an informal question guide (Appendix) derived from a focused literature review (Brooks and others 2006a). All questions were asked in each interview; however, the interviewers allowed spontaneous conversations about risk mitigation to emerge and be recorded.

To begin, we interviewed 6 individual key informants. This was followed by 11 focus group interviews. Combined with the individual interviews, 61 people participated. Focus groups represented many of the key stakeholders involved with this issue. The groups interviewed were selected by peer referral or snowball sampling (Miles and Huberman 1994). The individual interviews were audiotaped and transcribed, and the focus groups were videotaped and audiotaped and transcribed to yield a total of 472 single-spaced pages.

We separated the interviewees into two groups: producers and consumers. We categorized producers as interview participants and groups who have a direct role in the partnership's mission and its execution, particularly its objectives for communicating with the public. The producers literally have a seat at the table. The six producer interviews included an individual interview with a federal public affairs officer, focus-group interviews with the partnership's communications and management teams (one interview with each team), and focus groups with representatives from three nongovernmental organizations 
(NGOs). The NGOs included two conservation organizations and one watershed advisory board. Leaders of the partnership invited representatives from these NGOs to participate in planning discussions after they had directly asked the partnership to be formally included. ${ }^{2}$

We categorized consumers as those outside the producer group; they may be interested in and even observe the partnership, but they have no formal opportunity to participate. We conducted five individual interviews with consumers, including a county wildland fire specialist, a county extension agent, a state funding specialist, a social scientist, and a husband and wife living in an interface forested area. ${ }^{3}$ Focus group interviews with consumers included a group of volunteer firefighters, an interface homeowners' group, a local organization working to decrease fuels, a group of journalists who cover wildfires, a group of researchers, and representatives of a plains community that coordinates efforts to suppress grassland fires in eastern Colorado. ${ }^{4}$

Analysis of data occurred in a five-stage process (Champ and others 2009): (1) discussions between the interviewers immediately after each interview; (2) in-depth study of individual interviews and focus groups to gain a deep understanding of each informant and stakeholder group (Patterson and Williams 2002); (3) tracking topics (i.e., categories and themes) that emerged within and across interviews during verbatim transcription (Hoover and others 2004; Patterson and Williams 2002); (4) repeated readings, discussions, and negotiations about topics in the transcripts by two team members while searching for additional topics (Hoover and others 2004); and (5) use of qualitative analysis software (ATLAS.ti [version 5.0], ATLAS.ti GmbH, Berlin, Germany) by one analyst as a tool to manage the data and comprehensively code, query, and compare shared and differing meanings across interviews (Patterson and Williams 2002).

While coding the topics, we assessed the tone of the discussion and cross-coded transcripts in terms of whether

\footnotetext{
${ }^{2}$ Note that these environmental advocacy groups may identify with both consumers and producers, as evidenced in this focus group excerpt: “... we are a conservation group-a science-based conservation group - and our mission is to protect biological diversity. I think that every problem that you work on in forest health you take a broad view and think about community needs and everything else as a necessary part of protecting biodiversity, but the lens through which we look at forest health tends to focus on protection of biodiversity and the importance of forest health... recognizing that community protection is an important issue that is being addressed as well." Despite that, we are labeling them as producers because of their close relationship with the Partnership, particularly their direct participation in Partnership planning.

3 This couple requested that they be interviewed together. We treated it as an individual interview.

4 This last group was included for comparative purposes to see how a grassland community functioned in comparison with a forested community in the foothills or mountains.
}

statements expressed barriers or facilitators. The coding software allowed us to demonstrate the prominence of particular topics across the interviews, how often those topics were associated with barriers or facilitators, and which producers and consumers felt one way or the other about particular topics. We used Fig. 2 to organize and present our findings and bring order to the interview data (Tesch 1990, p. 139). ${ }^{5}$

\section{Findings}

We identified $>300$ separate topics in the interview transcripts. These topics were organized under several broad codes (i.e., communication, funding, philosophy, stakeholders, policy, wildland fire, and wildland-urban interface [WUI $\left.\left.{ }^{6}\right]\right)$. We used Figure 2 to summarize our findings and comparison of producers and consumers according to three key themes: (1) barriers and facilitators (i.e., qualitative value), (2) shared meanings (i.e., articulation), and (3) differing meanings (i.e., lack of articulation).

\section{Barriers and Facilitators}

It became evident that both producers and consumers discussed ideas related to wildland fire and fuels reduction in a dichotomous way. It was common to hear stories that communicated what we considered a negative value, which we coded as barriers, such as this excerpt in which a government public affairs officer described one challenging aspect of her job:

\footnotetext{
${ }^{5}$ Figure 2 is a helpful, yet coarse, representation of our interview interpretations. The order of themes in Fig. 2 is not meant to imply any sort of hierarchical order representing frequency, salience, or values in our interviews. Instead, it is intended to reflect general differences and congruencies between producers and consumers. It is helpful to think of Fig. 2 in terms of six zones: The themes producers consider to be facilitators (upper left); themes producers consider barriers (lower left); themes consumers consider facilitators (upper right); themes consumers consider barriers (lower right); themes both producers and consumers consider facilitators (upper middle); and themes producers and consumers consider barriers (lower middle). We located a theme in the central section of Fig. 2 (Shared Meanings) if producers and consumers seemed to share similar discussion frequencies, saliencies, and valuation on that topic. The themes were listed on the left and right zones of Fig. 2 if the producers and consumers differed on frequency and/or saliency and values. Within each zone, the order of themes generally follows the order within the discussion of this article.

${ }^{6}$ The WUI is an exurban region where human development meets and mixes with undeveloped, often forested landscapes such as foothills or mountains. In recent decades, more people have migrated to live in the WUI because of the attractiveness of what is thought to be a pristine, authentic, rural lifestyle with access to amenity resources. Many WUI residents have had to confront natural threats such as encounters with wildlife and wildland fires.
} 
Fig. 2 Interpretation of producer and consumer themes

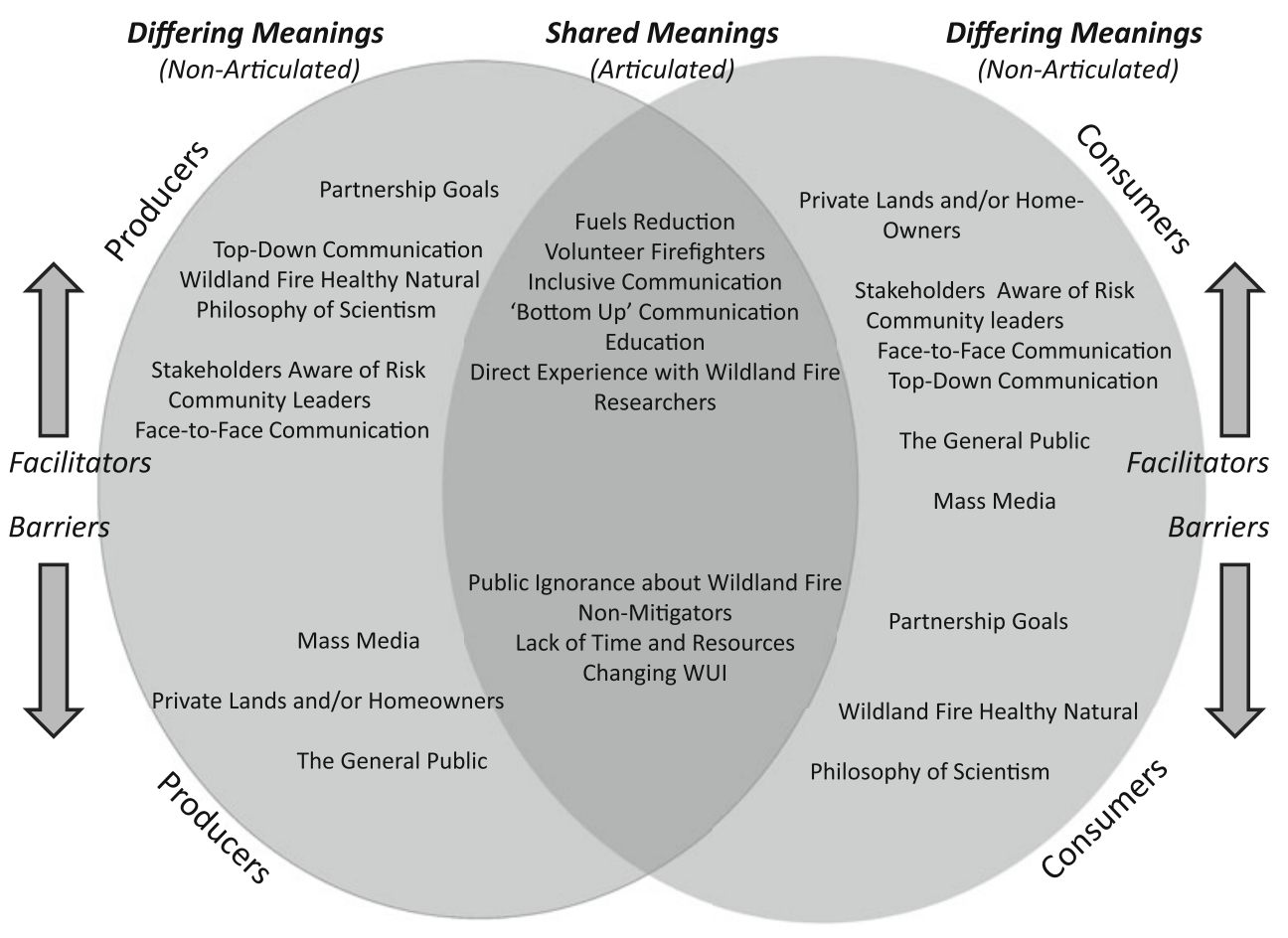

... there is this attitude out there about, 'We're from the government, and we're here to help you,' and quite frankly, most people (laughing a little)... They see us come out there, and we've got a uniform on, it's like, 'Don't even come on my land!'

It was nearly as common to hear the opposite-positively valued stories-which we coded as facilitators. In this excerpt, the caretaker of a subdivision located in a heavily forested, fire-adapted area noted the positive potential of community attachment.

$\ldots$ it has been a royal project in a lot of different ways, but we still love it, and if you love a community, you still try to do everything that you can to take care of it.

Early in the research we discussed the possibility that we should rely on a simpler dichotomy of "positive" versus "negative" statements, but we ultimately observed that the positive claims were communicating instances in which a participant's goals were being facilitated. Conversely, the negative statements reflected a sense of barriers to one's goals.

\section{Shared Meanings}

We found evidence of a variety of shared meanings between producers and consumers. Wildland fire fuels reduction was the most often mentioned topic across the interviews. This topic was frequently discussed by both producers and consumers. We observed a substantial overlap in understandings of fuels reduction to be a facilitator for both producers and consumers (Fig. 2). It makes sense that the producers (i.e., those formally associated with the partnership) would optimistically view fuels reduction as a facilitator because they are directed by agency policy to mitigate the threat of wildland fire by decreasing fuels. Moreover, the positive benefits of fuels reduction is precisely the message the producers wish to communicate. We also observed consumers describing fuels management as positive in many of their interviews, such as this quote from a man who valued the increased networking potential of being part of a community wildland fire organization:

... many different mitigation concerns get brought to the table that we might not be aware of with our own little sphere of influence, and we can share stories, and although we have an awful lot of differences that are unique to our little areas, there are a lot of commonalities. And by sharing those and by sharing solutions to those- - I think it puts us all ahead of the game.

Both groups appear to understand the role of volunteer firefighters and their departments in encouraging and facilitating fuels reduction. For example, a representative of an NGO that is part of the partnership (i.e., producer) underscored the importance of shared meanings with volunteer fire departments, "It is great because we are all talking the same talk. We are all saying the same things about fire and fire management." 
Both producers and consumers generally expressed agreement about the importance of practicing inclusive communication to build relationships. One member of a community wildfire risk-mitigation group not involved with the partnership (i.e., consumer) has seen an evolution in the way the United States Forest Service has reached out to communities after a number of devastating wildfire events.

Before the fires, I saw this real clear separation between the private lands and the public lands, or the federal Forest Service. I think because of the fires and seeing that fact that we have subdivisions surrounding the Forest Service [land], and that really impacts the Forest Service [management] of those public lands-I see that they are moving toward learning to work with the private lands also, and learning to do it cooperatively and you must look at things on a watershed basis.

This comment also provides evidence that both producers and consumers in our study understand bottom-up communication (i.e., communication that encourages participation from those who are normally outside the decision-making agencies, such as the consumers in this study) to be a facilitator. In addition, both producers and consumers shared an understanding of the contribution of education in increasing awareness of the issues.

The producers and consumers expressed agreement that direct experience with wildland fire (e.g., actually having witnessed and/or been threatened by wildfire) generally results in favorable responses to mitigation measures. One community leader from the consumer group saw big changes in mitigation behavior of second homeowners after a wildfire that threatened their subdivision.

... I know before they were coming up to relax and enjoy, and they didn't really realize how much could and how quickly it did happen, and I think now it is more, 'Oh boy, that really can happen! and we must be more prepared.'

There appeared to be a sense in both groups that the work of researchers of wildland fire-related issues, both ecological and social, could be beneficial. In fact, in a focus group with NGO members associated with the partnership, respondents expressed enthusiasm for our examination of the organization. "I think that it is encouraging that they launched you guys on this mission. I sense a genuine desire to figure out this collaboration thing and how to do this."

In terms of barriers, the producers and consumers both pointed to the problem of public ignorance about wildland fire issues. Although we did not survey the public at large, these stakeholders perceived levels of ignorance in the general public regarding wildfire risk and its mitigation. This makes sense for the producer group with a goal of spreading the word about wildfire-risk mitigation, but it also was common among interviewees who represented the consumer group. For example, one community member, working with a wildfire risk-mitigation group, underscored a particular problem with realtors refusing to disclose to potential buyers the fact that many interface properties are at risk of wildland fire.

I had a realtor come to my house this weekend because I'm contemplating selling it, it's simply too big, and I wanted him to evaluate it, what it might be worth, and I told him that I had performed the wildland fire mitigation on my lot, and we have an active program in the neighborhood, and he said, 'Well, we won't mention that because people won't want to hear about fire.'

In a related topic, producers and consumers were generally critical of nonmitigators, defined as people who live in or near the forest and who do not actively remove or otherwise control the potential flammability of fuels on their properties. Again, this is understandable among producers, but it was interesting to see how consumers shared this concern. Another WUI resident, working with a wildfire risk-mitigation group and representing consumers, stated, "I live in an area where citizens just believe that, 'No, just leave everything alone. I want to keep this natural,' and it's frightening to me."

One caution, however, is the fact that it can be difficult in this type of research to successfully recruit participants who do not manage fuels or take other measures to mitigate risks; those who do not mitigate are less likely to take part in such a study (Brenkert-Smith and others 2006). For example, one interviewee (part of the journalist focus group and a WUI homeowner) openly confessed her failure to mitigate.

It's overwhelming; I can't even begin to think about any of that. I'm trying to get my dishes done every day. I'm just trying to live much less mitigating around my house. We're talking about new landscaping. We're talking about [new] roofs.

As reflected in this excerpt, we observed shared concerns among producers and consumers about the lack of time and resources available for mitigation (i.e., capacity issues). In a majority of the interviews, both groups also discussed the negative aspects of a changing WUI, including more people and development moving in, which is believed to put greater pressure on the forest ecology and forest managers.

\section{Differing Meanings}

There is much we can learn about how producers and consumers seem to articulate, or share, meanings. However, as discussed previously, we also have much to learn 
from the ways in which cultural processes do not articulate but differ (Hall 1997, pp. 234-238). We observed such differences for producer and consumer groups in a number of topic areas (Fig. 2). For example, whereas the producers were more likely to cast mass media in a negative light in terms of their coverage of wildland fire issues, the consumer interviews expressed ambivalence (this is represented in Fig. 2 as lying on the border between Facilitators and Barriers [see right-hand center of diagram]). Because the producers are affiliated with institutions (i.e., agencies and organizations) that both depend on and are occasional targets of what were perceived to be negative, or inaccurate, media reports, it was more common for producers to see media as barriers to their efforts. In support of this observation, Fearn-Banks (2002, p. 65), studying crisis communication, wrote, "... a negative story is deemed more newsworthy than a positive one."

Another difference involved discussions about the partnership's goals for fuels reduction. We observed the producers expressing their goals as positive facilitators. The consumers, however, tended to view the goals of the partnership as barriers. One member of a group doing wildfire-risk mitigation questioned the partnership's commitment to truly involve private landowners.

I just don't see it in the [partnership] plans. The maps still end at the forest boundary, and yes, they appear to be moving treatments in the direction of homes, but it doesn't appear that they are actually planning landscape scale fuel treatments.

More importantly perhaps was a difference in the amount of discussion devoted to the partnership. All of the producer interviews involved extensive discussions of the partnership, but it was only meaningfully discussed in 6 of the 11 consumer interviews. In almost every one of these interviews, the participants expressed a lack of knowledge and awareness of the partnership and its goals, such as in this excerpt from a focus group with homeowners living in an interface community.

"How many of you have heard of the Front Range Fuels Treatment Partnership?" (This question was followed by silence.) Homeowner 1: "No." Homeowner 2: "[We] never heard about it here." Homeowner 1: "Is this a recent development?"

From a public relations perspective, this lack of awareness of the partnership's work among stakeholders, who are important to the partnership, is arguably a problem. These citizens cannot engage with the partnership and come to understand its goals unless they know it exists.

Yet another difference involved a topic coded as topdown communication. One focus group participant, a partnership manager in the producer category, described:
It's top-down to strategize and educate and inform, coerce if we must, well we won't do that (all laugh loudly), but to stimulate conversation ...

Top-down communication originates among those having authority. These communicated representations, or messages, are imagined by those in authority to move, for the most part intact, "down" to those outside the institutions of power and authority. Top-down communication was understood to be a facilitator in a slight majority of the excerpts among both the producers and consumers. The two differed, however, in how salient this topic was to them as indicated by how much they had to say about top-down communication. Among the producers, we saw a relatively large number of excerpts associated with this topic: These excerpts were generated in five of the six interviews with producers. In contrast, top-down communication was mentioned in less than half of the consumer interviews.

The same general pattern held true for the topic coded as wildland fire healthy natural in terms of an ecological process. It was a popular idea among producers that wildland fire must return to its important role as an element of a healthy forest ecosystem. One producer, a watershed advisory group member, put it this way:

If we're managing the land right, we're restoring conditions that can then accommodate the right kind of fire ...

We did not see the same positive perceptions of returning fire to the landscape in the consumer group. This pattern was also evident in relation to the topic we coded philosophy of scientism. This topic is best summed up in this statement by a producer working for an NGO:

We have an incredible amount of scientific attention to fire ecology and fire management issues in Colorado that we must be gathering and applying as fast as possible. It is evolving really rapidly. It is a great case study in how important it is to incorporate science into decision making in a real-time basis. There are researchers out there right now today this minute gathering data that are going to inform where it makes the most sense to treat fuels and what the nature of those treatments ought to be.

We understand scientism to be the belief that science and its methods will ultimately provide humans with their best guide for existence (Leiss 1972). In this case, the best available science is considered to be a template, or model, for coexisting with wildland fire in healthy forests. Again, this was a common theme in producer interviews but not something developed or even discussed by the consumers.

We also observed interesting ambivalences in the way both groups discussed a topic that we coded as stakeholders 
aware of risk. Both producers and consumers expressed the positive belief that stakeholders realize that wildland fire risk exists in interface areas and that this awareness on their part is a facilitator. One consumer representative from a local fuels-treatment organization summarized:

First, you're looking at creating... awareness. Now I think that's been performed pretty effectively up and down the Front Range [in Colorado]. People are aware of the issue.

For producers, one partnership manager explained in a focus group interview:

I think the awareness is definitely coming. You know there's... just by the way people have backed off of the concerns about treatment of fire fuels in the forest. I think the fact that there's been, in general, pretty good acceptance of that legislation rather than just outright uninterrupted skepticism about it I think is just a good indication that a lot of awareness is coming along.

However, there was a substantial distinction in the saliency of this topic-a subtle yet potentially important fact not reflected in Fig. 2. It was observed only 7 times in the producer interviews but 28 times among consumers.

We see a similar pattern in discussions coded community leaders. Again, in these interviews, it is apparent that both producers and consumers generally speak favorably about the existence of community leaders as facilitators. For example, one producer, a conservation NGO representative, explained that "a good charismatic leader could do amazing things" in leading a community toward a healthy forest. However, the topic appears to be more prominent for consumers, with 26 excerpts in 8 interviews, compared with producers, who mentioned it just 8 times in 4 interviews.

The same is true with the topic of face-to-face communication. Both groups were more likely to speak positively about face-to-face communication as a facilitator of fuels reduction, but it was much more common for the consumers we interviewed, such as this social scientist who has studied the issue for years:

... we know from 100 years of cooperative extension and from other things, is what people really want is... to be talked to, and they want information that's available to them when they want it.

The interviews indicated that this topic was more salient among the consumers who brought up face-to-face communication 23 times in 10 interviews compared with producers mentioning it just 5 times in 4 interviews.

The discussion of the topic coded private lands and/or homeowners also showed differences. Producers discussed this topic at length, more often than not as a perceived barrier to their success. A partnership manager explained:

... a key issue, and one we've been trying to figure out for a number of years is that whole social dynamics involved with how private landowners can be motivated to undertake mitigation efforts it seems to us, and we're too close to the subject, that anybody, once they're informed, should take action, and people have a million and one reasons why they don't want to do it, and they employ them all.

The topic of private lands and/or homeowners was not as commonly discussed by consumers, but when it was, it was more likely to be discussed in a positive way, indicating a perceived facilitator. One focus-group participant from a community wildland fire-mitigation group (i.e., a consumer) explained that a critical development in their efforts to improve fuels reduction was buy-in from private property owners. The 2002 Hayman fire prompted private property owners to work with the Forest Service and this mitigation group. "It took a catastrophic fire to get us all communicating better and doing things better (laughs), but at least we have come a long way since then," he said. The same pattern was observed in discussions of a topic coded the general public; we heard few comments from consumers about the general public but a notable level of comments among producers, indicating that they view the general public as a barrier to their work, such as this exchange between public affairs specialists (PAS) in the partnership:

PAS 1: Well they [the general public] don't see flames in their backyard, if they saw flames then they would get off dead center. PAS 2: (breaking in) However, it is human nature, part of that is human nature... PAS 1 : ... but by that time, it's too late... PAS 2: ... [same with] any hazard... PAS $1: \ldots$ and when the flames are gone, and they've had a little snow, a little rain, they say, "Ah, we've made it, we're safe." No, they're not. And you can only... you can lead a horse to water, but you can't make it drink.

\section{Implications and Recommendations}

The success of collaborative environmental management hinges on understanding communication processes and related barriers and facilitators (Brooks and others 2005; Jakobsen and McLaughlin 2004). In our interpretation of study findings, we discuss (1) the implications of contested meanings for the communicational efforts of the partnership while highlighting (2) how the partnership and outside stakeholders can capitalize on shared meanings of risk 
mitigation. Then we discuss some of the challenges and realities associated with (3) communication, (4) relationship building, and (5) agency authority. Throughout the remaining sections, we offer recommendations for overcoming the challenges and improving the practice of collaborative risk mitigation for all stakeholders.

\section{Contested Meanings}

We found a lack of articulation between the cultural processes of production and consumption (Fig. 2). We interpret the differences in meanings and understandings between the partnership and outside stakeholders as evidence that these two groups are constructing, or framing, risk mitigation/fuels reduction using different lenses. Brenkert-Smith and others (2006) found that different communities use different discourses to define and address issues of wildfire-risk mitigation. For example, wildfire is viewed by some communities as a prevention issue and by others as a response issue. Similarly, we found that the producers understand four key topics as facilitators for decreasing hazardous fuels: (1) the goals of the partnership, (2) fire's role in healthy ecological processes, (3) top-down communication, and (4) management based in science. We suggest that these findings indicate that a discourse of scientific management is driving communication for producers. For many of the producers, the priority solution to the problem of wildland fire and fuels management is approaching it in a systematic scientific way. The producers believe that the success of wildland fire management results from a process of thoroughly and rigorously showing the truth of forest health and ecology. The information they amass through the methods of science (i.e., truth) will then be communicated to homeowners and members of the public living in and near fire-adapted lands. The producers aim to give the consumers the proper tools to make decisions so that they behave appropriately in relation to wildland fire. We see this discourse of rational and science-based management in the frequent and positive discussions of these topics by the producers.

However, communication based in a discourse of scientific management appears to be the opposite of how the consumers understand the problem in this case. The lower right-hand section of Fig. 2 shows that consumers view (1) the goals of the partnership, (2) wildland fire as a healthy ecological process, and (3) a management philosophy based in science to be barriers to addressing the problem. The consumers were more likely than the producers to view private landowners, homeowners, and the general public as facilitators. Unlike producers, the consumers more frequently and positively discussed community leadership and face-to-face communication as facilitators for addressing risk mitigation. We interpret the divergent discussions of the producers and consumers about these topics as evidence that consumers are framing the problem using a discourse of community.

Contested meanings indicate that the producers and consumers understand, and thus communicate about, wildfire-risk mitigation in different ways. In this case, the partnership places trust and authority in a model of scientific management, whereas the stakeholders outside the partnership place trust and authority in private property owners and community structure, values, and leadership. These differences can produce barriers to success for the communicational efforts of the partnership. It is part of the resource manager's stewardship role to identify and remove barriers to understanding that can interfere with protection of natural resources (Brunson 1992, p. 293). Managers and policymakers must first recognize that some stakeholder groups define wildfire-risk mitigation using discourses that differ from their own. Then the producers should give alternative discourses equal weight and perhaps equal authority during collaboration, communication, and education. The producers in this case should work more closely with the consumers to learn how to speak a community language in addition to, and perhaps in concert with, their language of scientific management when communicating about wildfire-risk mitigation. This can allow stakeholders to begin to develop and speak the same riskmitigation language (Paveglio and others 2009; Zaksek and Arvai 2004) and take a different perspective (Weber and Word 2001) on the wildland fire problem in interface areas. The new frame of reference is different in that it is a shared perspective or hybrid of the original discourses of scientific management and community.

\section{Shared Meanings}

To begin to develop a common language and shared frame of reference, both producers and consumers should pay close attention to the shared meanings identified in this study. That is, how do meanings overlap or articulate for producers and consumers (Fig. 1)? For example, both groups view volunteer fire departments as facilitators for decreasing fuels in interface communities. Volunteer fire departments are embedded in local communities and should be enlisted by both the partnership and the communities as liaisons for communicating about risk mitigation. Members of local volunteer fire departments and other community leaders can act as sounding boards for how different agency ideas and plans may or may not contribute to decisions about risk mitigation at the local level.

Experience with wildfire, forestry, or agriculture and time spent living in interface areas tends to increase people's knowledge and awareness of wildfire risks (McGee and Russell 2003). Similarly, producers and consumers 
interviewed in this study agreed that direct experience with wildland fire generally results in favorable responses to mitigation measures. Agency managers should identify and invite well-respected leaders and fire fighters living in interface communities, and who have experienced fire events in the past, to go with them to visit communities that are at risk but have not yet been threatened by an event. Both groups could ask such experienced opinion leaders to help design and deliver key mitigation messages.

We found evidence that both producers and consumers understand that inclusive bottom-up formats work best for communicating about this problem. The two groups think that education and research can facilitate wildfire-risk mitigation. The producers should closely involve the consumers in developing media as well as planning and implementing education programs and research studies. Scientific research can help inform the development of a shared discourse of wildfire-risk mitigation in interface areas, and scientists can evaluate the success of mitigation decisions (Thomas and Burchfield 1999).

Time, resources, and other capacity issues have been identified as factors that influence the outcomes of collaborative resource management (e.g., Cheng and Mattor 2010; Schusler and others 2003). In this study, producers and consumers both view lack of time and resources as barriers to addressing the problem. The partnership and outside stakeholders should prioritize creative solutions to these basic capacity issues. This will remain a major challenge in current times of decreasing agency budgets and economic recessions.

The articulated meanings shown in the center of Fig. 2 represent some common ground on which the partnership and outside stakeholders can build. It will remain important for all partners to understand that the commonalities they may build together and share will change as stakeholders, interface areas, and agency policies change through time.

\section{Two-Way Communication}

The professional culture of natural-resource management has tended to over-rely on technical expertise and sound judgment, purportedly grounded in the best-available science (Brunson 1992; Haas 2003; Nelson 1999). Until recently, the general thrust of agency communication about wildfire risk was a unidirectional flow of information from experts to citizens (Paveglio and others 2009, p. 81). Our analysis supports the existence of this traditional narrative in relation to the partnership's efforts to communicate with outside stakeholders. Critics (Curtin and Gaither 2005, 2006, 2007) have questioned such normative, functional approaches to communication that they believe fail to properly represent "the dynamic characteristics of [human] relationships and discursive nature of meaning" (2005, p. 91). They argue that often it is not as simple as delivering an effective message from sender to receiver. Forces throughout the communicational process vie for legitimacy and control in ways that may defy even the most effective message strategies, such as differing frames of reference and professional biases (Brunson 1992; Weber and Word 2001).

In the context of wildfire risk, some research has shown that interactive symmetrical communication (Grunig 1992) is preferred by members of the public and proves to be more effective for learning about and increasing acceptance of mitigation options than unidirectional top-down formats (e.g., Edwards and Bliss 2003; Farnsworth and others 2003; McCaffrey 2004; Monroe and others 2003; Monroe and Nelson 2004; Toman and others 2006). Agency experts who use face-to-face two-way formats seek to create an open line of communication between parties in which messages back-and-forth are honestly considered. This requires a willingness of all parties to adjust their views and understandings of the problem, redefine it, and arrive at common ground. Doing so can ensure success in terms of both balancing and valuing the viewpoints and needs of all involved. In this way, it is assumed that land managers and other stakeholders can learn from one another and proceed in the best interests possible for all.

Although we see this as a positive development in both natural resource and wildland fire communications practice and research, we remind readers that this model has been critiqued, particularly in critical and postmodern public relations scholarship (Duffy 2000; Roper 2005). These researchers argue that the presentation of equality in communication is often a ploy that hides true arrangements of power between players with unequal authority, thus serving to ward off disapproval of unfair relationships while maintaining the status quo.

\section{Overcoming Challenges in Relationships}

We illustrate a critique of the status quo with the words of a public affairs officer, who is charged with representing the partnership but dubious about his agency's ability to build the relationships required to successfully communicate about wildfire-risk mitigation:

I'm seeing a relatively painful, slow change. When we were first dealing with wildfire, and even prescribed fire, it was a matter of providing information, and now, you take this agency that culturally is not really tuned into anything but providing information from the scientific standpoint, from an effects standpoint ... we just focused on the [fire] event, and we said, 'This is what happened, this is what's going to happen,... your house is gone.' Now, because of 
having to work with people, and having to work with that social side, our communications efforts are moving toward more relationship-building. We have absolutely no expertise in that, none at all. Nor do we have the type of information that we would need to start developing it. I truly believe, and this is a personal opinion, that we do not have the personalities in the agency along with the culture to really develop relationships.

Perhaps the first step in addressing the concerns of this public affairs officer involves recognizing and properly valuing the range of potential meanings that surround any given interface situation. We have attempted to demonstrate that it is not enough to account for meanings of producers and consider the task complete. One must also consider meanings of consumers, including the way these meanings may both align and compete with those of the producers. Furthermore, these arrangements may change over time. We believe that informing communication with Circuit of Culture research can ease situations, such as those described by this public affairs officer, and contribute to increased levels of trust and working relationships between agency managers and other stakeholder groups. In the past, these agencies have almost exclusively focused on the moment of production as illustrated in the statement of the public affairs officer. The Circuit of Culture prompts us to truly pay equal attention to cultural participants that might not otherwise be heard (i.e., the consumers in this study) and also critically evaluate the assumptions and intentions of those in the more powerful position (i.e., the producers in this study). The Circuit of Culture model helps us demonstrate how meaning does and does not overlap or articulate (Hall 1997, p. 234-238). Further research in this arena can help managers to both understand and provide the necessary "expertise" and "culture" to really develop relationships.

In addition, managers should ensure that stakeholders are adequately aware of their management programs (Paveglio and others 2009), an issue that emerged in our research when it became clear that many consumers had not heard of the partnership or its goals. Increasing awareness of such collaborative partnerships may be facilitated by crafting programs that are community oriented and less focused on expert-driven management and the science of ecological health and restoration. Increasing awareness of the goals of the partnership can help to decrease the divide in understanding between agency experts and the communities they serve and, at the same time, increase both trust and shared meanings.

We do not recommend that science-informed management be abandoned; rather, substantially more thought should be directed at the way desired scientific and management practices might coexist with the mitigation goals of interface communities and other external stakeholders. To do this, managers should recognize the historical and cultural realities of interface communities and work with members to learn how those communities understand and value information about wildfire-risk mitigation (Mendez and others 2003). That sort of understanding on the part of agency experts requires careful listening, observation, and sensitivity to unique social arrangements and community histories and values. This requires a revised planning and decision-making process (Arvai and others 2006) based on a different perspective; it "means assimilating and accommodating others' frames of reference" (Weber and Word 2001, p. 493). Although managers rarely have the time and resources to engage in lengthy interviews, workshops, or community-listening sessions, they should give these activities higher priority as tools for building relationships with communities and other consumer groups.

\section{Agency Position of Authority}

Despite the case that we gave equal interpretive weight to those within as well as outside the partnership, the first implication for management is to recognize that meanings held by producers usually will carry more weight in decisions about natural-resource management. Agency managers and decision makers are often in a position that allows them to define environmental problems as they see them and control cultural processes, such as communication and collaboration. After all, differing frames of reference arise from actual differences in power among individuals and between individuals and institutions (Weber and Word 2001, p. 493). This position of authority can intentionally or unintentionally create and enforce unequal positions for those participants who are not powerful enough to control the construction and negotiation of the multiple meanings surrounding complex environmental problems. Moreover, these power dynamics significantly predate contemporary wildland fire issues. Carroll and others $(2007$, p. 240$)$ argued that the wildland fire controversy in the United States has been building for more than 100 years:

This controversy, we argue, is another chapter in the longer-standing debate over the management and condition of public forests, in which terms such as 'forest health' and 'forest restoration' have been used by opposing sides to win public support for their preferred policy objective.

Although recognizing and acting responsibly from this position of authority is the ethical thing to do, in the long 
run producers may encounter difficult obstacles in their efforts to communicate if they consistently fail to recognize the understandings and meanings of consumer groups outside the partnership. We recommend that resource managers think of human experience in terms of a cultural dialogue in which meanings are continually negotiated and to remember that those negotiations are not always fair and equal.

\section{Conclusion}

This study underscores the importance of being realistic and honest with constituents. Brooks and others (2006b, p. 40) advised, "Practitioners can start by honestly telling communities that there is no guarantee that enough resources exist to stop all interface fires that might threaten them." Wildfire-risk communication is a process with no beginning, no ending, and no right or wrong solutions. Managers and policymakers cannot and should not attempt to define the general public and private landowners in ways that they hope will generate expert-derived solutions. In the context of wildfire-risk mitigation, communicators should not rely on persuasion to change the behaviors of consumers. That perpetuates a relationship of the powerful with the powerless. Instead, all parties must understand that healthy communities and healthy forests require healthy relationships, which in turn, require an open dialogue framed as a never-ending and articulating process in the Circuit of Culture.

Acknowledgments This research was supported in part by funds provided by the United States Forest Service, Rocky Mountain Research Station in Fort Collins, Colorado, USA. The findings and conclusions are those of the authors and do not necessarily represent the views of the United States Fish and Wildlife Service.

\section{Appendix: Interview Question Guide}

\section{Part A: Fire History}

(For homeowners, recreationists, and other representatives of organizations outside direct partnership participation): Has your home/property/favored place/study site(s)/jurisdiction ever been threatened by fire?

(For agency/NGO personnel [i.e., partnership participants]): What sort of fire activity has occurred in the region(s) you manage/focus on?

\section{Part B: General Management History}

(For homeowners, recreationists, and other representatives of organizations outside the partnership): What has been the history of wildfire management for your home/property/favored place/study site(s)/jurisdiction?

(For agency/NGO personnel): How have you managed/ focused on for wildland fire in the past?

\section{Part C: Individual Management History}

(For homeowners, recreationists, and other representatives of organizations outside the partnership): What has been your history with fuels mitigation (i.e., defensive strategies to minimize wildfire intensity) around your home/property/ favored place/study site(s)/jurisdiction?

Part D: Mapping Informational Pathways

How have you heard/learned about wildfire management?

Probes: (For homeowners, recreationists, and other representatives of organizations outside the Partnership]: Do you learn from agency communications (i.e., face-to-face meetings, literature, Website(s)? From the news media? From local government or local organizations? From family, friends, neighbors, business owners? From other?

(For agency/NGO personnel): What is the educational, scientific and philosophical background for your approach to wildland fire management? How do you interact/communicate with the public about wildland fire management?

Part E: Best-Management Practices (i.e., Ideas About How It Should Take Place)

(Same question for all): In your opinion, what is the best way to manage for fire along the Front Range?

Probes: Should we manage for fire along the Front Range, or should we let nature take its course? The president and others are calling for increases in tree harvest in the Western forests? Do you think this is a good idea? Why or why not?

Part F: Communications (If They Haven't Already Discussed These Issues in the Previous Question)

(For homeowners, recreationists, and other representatives of organizations outside the Partnership): Do you ever think about the ways that land and fire managers communicate about fuels treatment? [If they report thinking about it] Are you satisfied with this communication? If yes, how? If no, why not?

(For agency/NGO personnel): What strategies have you used to communicate about fuels treatment? Do you have a way to gauge public reaction to this communication? Are 
you satisfied with this communication? If yes, how? If no, why not?

Probes: For example, public meetings; phone calls; mailings; public service announcements in the newspapers, radio, television; videotapes, CDs, and DVDs; Web site(s); other?

\section{Part G: The Front Range Fuels Treatment Partnership}

(For homeowners, recreationists, and other representatives of organizations outside the Partnership): Have you ever heard about The Front Range Fuels Treatment Partnership? If so, what have you heard? [If not, ask them to describe the partnership and its mission.] How do you feel about the creation of an organization such as the Front Range Fuels Treatment Partnership?

(For agency/NGO personnel): Could you share your thoughts about The Front Range Fuels Treatment Partnership? Positives? Negatives? Ways to improve (or is it already effective)?

\section{Part H: The Collaborative Process}

We realize it may seem to be a little unusual to join a group of strangers (if they were previously unfamiliar with one another) to share your views about wildfire management, but how did you feel about the process?

Probes: How did you feel about getting the opportunity to share your opinions with others. How did you feel about the responses of others in the group? Has this experience changed your feelings about wildland fire management in any way? Have your opinions stayed the same? Why or why not? If others had the opportunity to participate in this sort of exercise, do you think it would be beneficial? Why, or why not?

\section{References}

Acosta-Alzuru C (2003) "I'm not a feminist ... I only defend women as human beings": the production, representation, and consumption of feminism in a telenovela. Critical Studies in Mass Communication 20:269-294

Allen GM, Gould EM (1986) Complexity, wickedness, and public forests. Journal of Forestry 84:20-23

Arvai J, Gregory R, Ohlson D, Blackwell B, Gray R (2006) Letdowns, wake-up calls, and constructed preferences: people's responses to fuel and wildfire risks. Journal of Forestry 104(4):173-181

Benwell B (2003) Masculinity and men's lifestyle magazines. Blackwell, Oxford

Beringer J (2000) Community fire safety at the urban/rural interface: the bushfire risk. Fire Safety Journal 35:1-23

Brenkert-Smith H, Champ P, Flores N (2006) Insights into wildland fire mitigation: decisions among wildland-urban interface residents. Society and Natural Resources 19:759-768
Brooks JJ, Champ PA (2006) Understanding the wicked nature of "unmanaged recreation" in Colorado's Front Range. Environmental Management 38:784-798

Brooks JJ, Champ JG, Williams DR (2005) Toward understanding public-professional communication about wildland fire and fuels management in Colorado's Front Range. United States Department of Agriculture, Forest Service, Fort Collins

Brooks JJ, Bujak AN, Champ JG, Williams DR (2006a) Collaborative capacity, problem framing, and mutual trust in addressing the wildland fire social problem (RMRS-GTR-182). United States Department of Agriculture, Forest Service, Fort Collins

Brooks JJ, Brenkert H, Serby JE, Champ JG, Simons T, Williams DR (2006b) Integrating social science into forestry in the wildland/ urban interface. Fire Management Today 66(2):35-43

Brunson M (1992) Professional bias, public perspectives, and communication pitfalls for natural resource managers. Rangelands 14(5):292-295

Brunson MA, Shindler BA (2004) Geographic variation in social acceptability of wildland fuels management in the western United States. Society and Natural Resources 17:661-678

Burgess J (1990) The production and consumption of environmental meanings in the mass media: a research agenda for the 1990s. Transactions of the Institute of British Geographers 15:139-161

Busenberg G (2004) Wildfire management in the United States: the evolution of a policy failure. Review of Policy Research 21: $145-156$

Buxton M, Haynes R, Mercer D, Butt A (2011) Vulnerability to bushfire risk at Melbourne's urban fringe: the failure of regulatory land use planning. Geographical Research 49(1):1-12

Carroll M, Daniels S (2003) Fire in our midst: a look at social science research issues at the community level. In: Cortner HJ, Field DR, Jakes P, Buthman JD (eds) Humans, fires, and forests-social science applied to fire management. Ecological Restoration Institute, Flagstaff, pp 17-94

Carroll MS, Blatner KA, Cohn PJ, Morgan T (2007) Managing fire danger in the forests of the US inland Northwest: a classic "wicked problem" in public land policy. Journal of Forestry 105(5):239-244

Champ JG (2008) Horizontal power, vertical weakness: enhancing the "Circuit of Culture". Popular Communication: The International Journal of Media and Culture 6:85-102

Champ JG, Brooks JJ (2010) The Circuit of Culture: a strategy for understanding the evolving human dimensions of wildland fire. Society and Natural Resources 23:573-582

Champ JG, Williams DR, Knotek K (2009) Wildland fire and organic discourse: negotiating place and leisure identity in a changing wildland urban interface. Leisure Sciences 31:237-254

Cheng AS, Becker DR (2005) Public perspectives on the "wildfire problem". Fire Management Today 65:12-15

Cheng AS, Mattor KM (2010) Place-based planning as a platform for social learning: insights from a national forest landscape assessment process in Western Colorado. Society and Natural Resources 23:385-400

Cohen JD (2008) The wildland-urban interface fire problem: a consequence of the fire exclusion paradigm. Forest History Today (Fall):20-26

Cortner HJ, Gale RD (1990) People, fire, and wildland environments. Population and Environment 11:245-257

Curtin PA, Gaither TK (2005) Privileging identity, difference, and power: the Circuit of Culture as a basis for public relations theory. Journal of Public Relations Research 17:91-115

Curtin PA, Gaither TK (2006) Contested notions of issue identity in international public relations: a case study. Journal of Public Relations Research 18:67-89

Curtin PA, Gaither TK (2007) International public relations: negotiating culture, identity, and power. Sage, Thousand Oaks 
Dale L (2006) Wildfire policy and fire use on public lands in the United States. Society and Natural Resources 19:275-284

Daniels SE, Walker GB (1996) Collaborative learning: improving public deliberation in ecosystem-based management. Environmental Impact Assessment Review 16:71-102

Davis JB (1990) The wildland-urban interface: paradise or battleground? Journal of Forestry 89:26-31

Davis J, Marker J (1987) The wildland/urban fire problem. Fire Command 54:26-27

Dean D, Jones C (2003) If women actors were working.... Media Culture and Society 25(4):527-541

Donovan GH, Brown TC (2007) Be careful what you wish for: the legacy of Smokey Bear. Frontiers in Ecology and the Environment 5(2):73-79

du Gay P (ed) (1997) Production of culture/cultures of production. Sage, London

du Gay P, Hall S, Janes L, Mackay H, Negus K (1997) Doing cultural studies: the story of the Sony Walkman. Sage, London

Duffy ME (2000) There's no two-way symmetric about it: a postmodern examination of public relations textbooks. Critical Studies in Media Communication 17:294-315

Edwards KK, Bliss JC (2003) It's a neighborhood now: practicing forestry at the urban fringe. Journal of Forestry 101(3):6-11

Farnsworth A, Summerfelt P, Neary DG, Smith T (2003) Flagstaff's wildfire fuels treatments: prescriptions for community involvement and a source of bioenergy. Biomass and Bioenergy 24:269-276

Fearn-Banks K (2002) Crisis communications: a casebook approach. Lawrence Earlbaum, Mahwah

Findley AJ, Carroll MS, Blatner KA (2001) Social complexity and the management of small-diameter stands. Journal of Forestry 99:18-27

Forests and Rangelands (2011) A national cohesive wildland fire management strategy. Forests and Rangelands. http://www.forest sandrangelands.gov. Accessed 16 Dec 2011

Freeman M (2006) Nurturing dialogic hermeneutics and the deliberative capacities of communities in focus groups. Qualitative Inquiry 12(1):81-95

Gill AM, Stephens SL (2009) Scientific and social challenges for the management of fire-prone wildland-urban interfaces. Environmental Research Letters 4:1-10

Glaser BG, Strauss AL (1967) The discovery of grounded theory: strategies for qualitative research. de Gruyter, New York

Gorte RW (2008) Wildfire damages to homes and resources: understanding causes and reducing losses. Congressional Research Service, Washington

Greenbaum TL (2000) Moderating focus groups: a practical guide for group facilitation. Sage, Thousand Oaks

Grunig JE (ed) (1992) Excellence in public relations and communication management. Lawrence Erlbaum, Hillsdale

Haas GE (2003) Restoring dignity to sound professional judgment. Journal of Forestry 101:38-43

Hall S (1980) Encoding/decoding. In: Hall S, Hobson D, Lowe A, Willis P (eds) Culture, media, language. Hutchinson, London, pp $128-138$

Hall S (1994) Reflections upon the encoding/decoding model: an interview with Stuart Hall. In: Cruz J, Lewis J (eds) Viewing, reading, listening: audiences and cultural reception. Westview Press, Boulder, pp 253-274

Hall S (1996) Introduction: who needs ‘identity'? In: Hall S, du gay P (eds) Questions of cultural identity. Sage, London, pp 1-17

Hall S (ed) (1997) Representations: cultural representations and signifying practices. Sage, London

Hammer RB, Radeloff VC, Fried JS, Stewart SI (2007) Wildlandurban interface housing growth during the 1990s in California,
Oregon, and Washington. International Journal of Wildland Fire $16: 255-265$

Healthy Forests Initiative (2002) Healthy forests: an initiative for wildfire prevention and stronger communities. Healthy Forests Initiative, Washington

Healthy Forests Restoration Act (2003) Public law 108-148. http://www.fs.fed.us/spf/tribalrelations/documents/policy/statutes/ PL_108-148_HFRA.pdf. Accessed 12 Jan 2012

Holtzhausen DR (2000) Postmodern values in public relations. Journal of Public Relations Research 12:93-114

Hoover SM, Clark L, Alters A, Champ JG, Hood L (2004) Media, home, and family. Routledge, New York

Jakobsen CH, McLaughlin WJ (2004) Communication in ecosystem management: a case study of cross-disciplinary integration in the assessment phase of the Interior Columbia Basin Ecosystem Management Project. Environmental Management 33:591-605

Leiss W (1972) The domination of nature. George Braziller, New York

Levine E (2001) Toward a paradigm for media production research: behind the scenes at General Hospital. Critical Studies in Media Communication 18:66-82

Lijeblad A, Borrie WT, Watson AE (2009) Determinants of trust for public lands: fire and fuels management on the Bitterroot National Forest. Environmental Management 43:571-584

Lindlof TR, Taylor BC (2002) Qualitative communication research methods. Sage, Thousand Oaks

Mackay H (ed) (1997) Consumption and everyday life. Sage, London

McCaffrey SM (2004) Fighting fire with education: what is the best way to reach out to homeowners? Journal of Forestry 102(5): 12-19

McCaffrey SM, Moghaddas JJ, Stephens SL (2008) Different interest group views of fuels treatments: survey results from fire and fire surrogate treatments in a Sierran mixed conifer forest, California, USA. International Journal of Wildland Fire 17:224-233

McGee TK, Russell S (2003) "It's just a natural way of life ..." an investigation of wildfire preparedness in rural Australia. Environmental Hazards 5:1-12

McKenzie D, Gedalof Z, Peterson DL, Mote P (2004) Climate change, wildfire, and conservation. Conservation Biology 18: 890-902

Mendez SR, Carroll MS, Blatner KA, Findley AJ, Walker GB, Daniels SE (2003) Smoke on the hill: a comparative study of wildfire and two communities. Western Journal of Applied Forestry 18:60-70

Miles MB, Huberman AM (1994) Qualitative data analysis: an expanded sourcebook, 2nd edn. Sage, Thousand Oaks

Mishler EG (1986a) Research interviewing: context and narrative. Harvard University Press, Cambridge

Mishler EG (1986b) The analysis of interview narratives. In: Sarbin TR (ed) Narrative psychology: the storied nature of human conduct. Praeger, New York, pp 233-255

Monroe MC, Nelson KC (2004) The value of assessing public perceptions. Wildland fire and defensible space. Applied Environmental Education and Communication 3:109-117

Monroe MC, Long AJ, Marynowski S (2003) Wildland fire in the Southeast: negotiating guidelines for defensible space. Journal of Forestry 101(3):14-19

National Academy of Public Administration (2004) Containing wildland fire costs: enhancing hazard mitigation capacity (1951-004). National Academy of Public Administration, Washington

Nelson RH (1999) Scientific management. Journal of Forestry 97(11):4-8

Nelson KC, Monroe MC, Fingerman Johnson J, Bowers A (2004) Living with fire: homeowner assessment of landscape values and 
defensible space in Minnesota and Florida, USA. International Journal of Wildland Fire 13:413-425

Norton A (1996) Experiencing nature: the reproduction of environmental discourse through safari tourism in East Africa. Geoforum 27:355-373

Patterson ME, Williams DR (2002) Collecting and analyzing qualitative data: hermeneutic principles, methods, and case examples. Sagamore, Champaign

Paveglio T, Carroll MS, Absher JD, Norton T (2009) Just blowing smoke? residents' social construction of communication about wildfire. Environmental Communication 3(1):76-94

Radeloff VC, Hammer RB, Stewart SI, Fried JS, Holcomb SS, McKeefry JF (2005) The wildland-urban interface in the United States. Ecological Applications 15(3):799-805

Rittel HJW, Webber MM (1973) Dilemmas in a general theory of planning. Policy Sciences 4:155-169

Roper J (2005) Symmetrical communication: excellent public relations or a strategy for hegemony? Journal of Public Relations Research 17:69-86

Russell RT (2003) Hayman fire case study: summary (RMRS-GTR115). United States Department of Agriculture, Forest Service, Rocky Mountain Research Station, Ogden

Schusler TM, Decker DJ, Pfeffer MJ (2003) Social learning for collaborative natural resource management. Society and Natural Resources 15:309-326

Shindler B, Toman E (2003) Fuel reduction strategies in forest communities: a longitudinal analysis of public support. Journal of Forestry 101(6):8-15

Shindler BA, Toman E, McCaffrey SM (2009a) Longitudinal analysis of public responses to wildland fuel management: measures to evaluate change and predict citizen behaviors in agency decision processes. Final Project Report No. 06-4-1-26. Joint Fire Science Program

Shindler BA, Toman E, McCaffrey SM (2009b) Public perspectives of fire, fuels and the Forest Service in the Great Lakes Region: a survey of citizen-agency communication and trust. International Journal of Wildland Fire 18:157-164

Shumway JM, Otterstrom SM (2001) Spatial patterns of migration and income change in the Mountain West: the dominance of service-based, amenity-rich counties. Professional Geographer 53:492-502

Slovic P (1999) Trust, emotion, sex, politics, and science: surveying the risk-assessment battlefield. Risk Analysis 19:689-701

Soar M (2000) Encoding advertisements: ideology and meaning in marketing production. Mass Communication and Society 3: 415-437

Squire SJ (1993) Valuing countryside: reflections on Beatrix Potter tourism. Area 25:5-10

Squire SJ (1994a) Accounting for cultural meanings: the interface between geography and tourism studies re-examined. Progress in Human Geography 18:1-16
Squire SJ (1994b) Gender and tourist experiences: assessing women's shared meanings for Beatrix Potter. Leisure Studies 13:195-209

Taylor BC, Demont-Heinrich C, Broadfoot KJ, Dodge J, Jian G (2002) New media and the circuit of cyber-culture: conceptualizing Napster. Journal of Broadcasting and Electronic Media 46:607-629

Terry V (2005) Postcard from the Steppes: a snapshot of public relations and culture in Kazakhstan. Public Relations Review $31: 31-36$

Tesch R (1990) Qualitative research: analysis types and software tools. Routledge Falmer, London

Thomas JW, Burchfield J (1999) The religion of forestry: scientific management. Journal of Forestry 97(11):10-13

Thompson K (ed) (1997) Media and cultural regulation. Sage, London

Toman E, Shindler B, Brunson M (2006) Fire and fuel management communication strategies: citizen evaluations of agency outreach activities. Society and Natural Resources 19:321-336

United States Department of Agriculture Forest Service (2003) Front Range fuels treatment partnership: a strategy to reduce wildland fire risks through sustained fuels treatment along the Colorado Front Range. Front Range Fuels Treatment Partnership. www.rocky mountainwildlandfire.info/frftp/frft_strategy.pdf. Accessed 19 Dec 2011

van Bueren EM, Klijn EH, Koppenjan JFM (2003) Dealing with wicked problems in networks: analyzing an environmental debate from a network perspective. Journal of Public Administration Research and Theory 13:193-212

Weber JR, Word CS (2001) The communication process as evaluative context: what do nonscientists hear when scientists speak? Bioscience 51(6):487-495

Westerling AL, Hidalgo HG, Cayan DR, Swetnam TW (2006) Warming and earlier spring increase western U.S. forest wildfire activity. Science 313:940-943

Western Governors Association (2001) A collaborative approach for reducing wildland fire risks to communities and the environment: a 10-year comprehensive strategy. United States Departments of Agriculture and Interior and the Western Governors Association

Wilcox SA (2003) Cultural context and the conventions of science journalism: drama and contradiction in media coverage of biological ideas about sexuality. Critical Studies in Media Communication 20:225-247

Winter G, Vogt CA, McCaffrey S (2004) Examining social trust in fuels management strategies. Journal of Forestry 102:8-15

Woodward K (ed) (1997) Identity and difference. Sage, London

Zaksek M, Arvai JL (2004) Toward improved communication about wildland fire: mental models research to identify information needs for natural resource management. Risk Analysis 24(6): $1503-1514$ 